\title{
Protective Effect of Quercetin against Oxidative Stress and Mitochondrial Bioenergetic Deficiency Caused by Lambda- Cyhalothrin
}

\author{
Nadia A. Hamed 1
}

\begin{abstract}
Mitochondria are a convenient model to understand the oxidative damage induced by various xenobioticprooxidants. This study was designed to investigate (1) the possibility of lambda-cyhalothrin (LCT), a type II pyrethroid, to induce oxidative stress response in rabbit liver mitochondria in vitro and its effect on selected parameters and (2) the role of quercetin in alleviating the cytotoxic effects of LCT. Mitochondria were divided into two groups. The first group, mitochondria were incubated for $30 \mathrm{~min}$ at $37^{\circ} \mathrm{C}$ with different concentrations $(0,5,10$, 15 and $20 \mathrm{uM}$ ) of LCT. In the second group, mitochondria were pre-incubated with $(10 \mu \mathrm{M})$ quercetin for $30 \mathrm{~min}$ and followed by LCT incubation for $30 \mathrm{~min}$ at $37^{\circ} \mathrm{C}$. Following in vitro exposure, LCT caused a significant induction of oxidative damage in mitochondria at all tested concentrations as evidenced by increased superoxide dismutase (SOD) activity and reduced glutathione (GSH) level. However, a significant decrease in the activities of NADH dehydrogenase and ATP synthase (ATPase) was obtained. While the quercetin treated mitochondria showed significant enhancement in all tested parameters except GSH content, there was no significant change. Quercetin showed a significant protection against the cytotoxic effects induced by LCT on the studied parameters. In conclusion, antioxidant quercetin could be able to ameliorate LCT-induced oxidative stress by altering antioxidant defense system and recovered the bioenergetic activity of mitochondria.
\end{abstract}

Keywords: Mitochondria, Lambda cyhalothrin, Qurcetin, Bioenergetic deficincey and oxidative stress.

\section{INTRODUCTION}

Pesticides are occasionally used in large amounts causing environmental pollution and health problems. Synthetic pyrethroids now account for more than $30 \%$ of insecticide due to their high efficacy, easy biodegradability, and low toxicity to birds and mammals. Lambda cyhalothrin (LCT) is a type II synthetic pyrethroid insecticide is widely used in Egypt for cotton, cereals and vegetables as well as in public health application against insect, ticks and flies (Abdel Aziz and Abdel Rahem, 2010). Residues of LCT have been reported in vegetables and fruits, milk and blood of dairy cows, and also in cattle meat (Muhammad et al., 2010; Turgut et al., 2011). Placental transfer of LCT has been observed in goats (Oliveira et al., 2000).

${ }^{1}$ Department of Mammalian Toxicology, Central Agricultural Pesticide Lab (CAPL), Agricultural Research Center (ARC), Alexandria, Egypt.

Corresponding author: nadia010560@yahoo.com

Received February 21, 2017, Accepted March 28, 2017
Consistent with its lipophilic nature, LCT has been found to accumulate in biological membranes leading to oxidative damage (Michelangeli et al., 1990; ElDemerdash, 2007; Fetoui et al., 2008 and 2010). However, in many cases the metabolism of xenobiotic substances can give rise to toxic metabolites or to reactive oxygen species (ROS) that can harm the cell further. Alterations in biochemical systems are often more sensitive indicators than those at higher levels of biological organization. Indeed, changes at the molecular level will underlie the effects at higher levels of organization. Pesticides are known to induce oxidative stress by inducing ROS production as byproducts of detoxifying metabolism, alternating the mitochondrial respiration or by their own redox (reduction/oxidation) cycling properties (Tebourbi et al., 2011).

Mitochondria are responsible for converting the energy released by electron transport and stored as the binding energy molecule ATP. NADH dehydrogenase, is the most complicated redox enzyme in mitochondria, it couples electron transport to proton translocation across the inner mitochondrial membrane. Consequently, in the process of oxidative phosphorylation, electrons generated from the oxidation of fuel molecules by oxygen are passed along a transport chain leading to the generation of ATP from ADP and inorganic phosphate through the master enzyme, ATP synthase (Hatefi 1985).

Dysfunction of mitochondrial energy metabolism leads to reduce ATP production, and generation of ROS such as superoxide anions, hydroxyl radicals and hydrogen peroxide (Cassarino and Bennett, 1999). ROS are increasingly recognized as playing an important role in many diseases because of their ability to cause oxidative stress and consequently damage cellular contents. Mitochondria constitute the major source of superoxide $\left(\mathrm{O}_{2} \cdot^{-}\right)$and other ROS within cells, generating approximately $85 \%$ of total cellular $\left(\mathrm{O}_{2}{ }^{-}\right)$, via aberrant $\left(\mathrm{O}_{2}\right)$ reactions (Droge, 2002). Mammalian mitochondria possess a multi-leveled ROS defense network of enzymes and nonenzymatic antioxidants. Manganese containing superoxide dismutase (MnSOD) protect cells from $\left(\mathrm{O}_{2} \cdot{ }^{-}\right)$attack by facilitating its dismutation into $\mathrm{H}_{2} \mathrm{O}_{2}$. Glutathione is considered the 
major antioxdiant molecule inside the cell. Approximately $\sim 90 \%$ of glutathione is in its reduced form, GSH ( $\gamma$-glutamylcysteinylglycine). GSH serves as a scavenger of hydroxyl radical thereby preventing free radical chain reaction ( $\mathrm{Ji}, 1999)$. Toxicity by oxygen radicals has been suggested as a major cause of cancer, aging, heart disease and cellular injury in hepatic and extrahepatic organs (Gram et al., 1986). Studies describing the oxidative stress mechanisms in pyrethroids-induced toxicity in mammalian mitochondria are limited. Few recent reports (Lim et al., 2009; Castanha Zanoli et al., 2012; Abdel-Razik and Hamed 2015) have demonstrated the induction of oxidative stress by other pesticides and its effect on mitochondria.

Plant-derived products are playing an essential role in the primary health care of about $80-85 \%$ of the world's population. Quercetin (3, 5, 7, 3', 4' pentahydroxyflavanone) is a plant-derived flavonoid present in foods (onions, citrus fruits, vegetables and grains) and beverages (tea and red wine) (Ikizler et al., 2007), inhibits oxidative stress induced by organophosphorous pesticides in experimental animals (Kalender et al., 2012). This flavonoid exhibits a wide range of biological activities including anticarcinogenic, anti-inflammatory, antiviral and antibacterial activities (Adewole et al., 2007). Many researchers have studied the in vitro cytotoxicity of different insecticides (Pardini et al., 1980; Pereira et al., 2009; Castanha Zanoli et al., 2012), while there is no enough data on the cytotoxic effects of lambda-cyhalothrin on mitochondria, therefore the present study aimed to investigate the In vitro effects of Lambda-cyhalothrin on the bioenergetics and the oxidative status of mitochondria isolated from rabbit liver.

\section{MATERIALS AND METHODS}

\section{1- Chemicals}

Lambda-cyhalothrin technical grade (98 \%) was obtained from Agromen Chemicals Co., Ltd, while Quercetin, $98 \%$ were obtained from Sigma Chemical Co. All other chemicals used in this study were of the highest purified grades purchased from Simga-Aldrich and Merck Chemical Companies.

\section{2 - Animals and care}

Male New Zealand White rabbits (age of seven months and initial weight of $2.873 \pm 0.0617 \mathrm{~kg}$ ) were used. Animals were individually housed in stainless steel cages at room temperature $\left(25 \pm 2^{\circ} \mathrm{C}\right)$ with a relative humidity of $50-60 \%$ and on a $12 \mathrm{~h}$ light-darkness cycle. The animals had free access to commercial pellet diet and water ad libitum. All maintenance and care were in accordance with the animal welfare guidelines established at the university.

\section{3- Preparation of mitochondria}

Rabbit liver mitochondria were isolated using a slightly modified protocol of Krause et al., (2005). The liver tissues were minced by a scalpel before disruption of the cells by a loose-fit glass teflon homogenizer with 4-5 strokes in 10 volumes of homogenization buffer (250 mM sucrose, $50 \mathrm{mM}$ Tris- $\mathrm{HCl}, 5 \mathrm{mM}$ EDTA, and $0.5 \mathrm{mM}$ phenylmethanesulphonyl fluoride (PMSF), $\mathrm{pH}$ 7.4). The homogenates were centrifuged at $800 \mathrm{~g}$ (10 $\min , 4^{\circ} \mathrm{C}$ ). The supernatants were layered on top of 350 $\mathrm{mM}$ sucrose, $50 \mathrm{mM}$ Tris-HCl, $5 \mathrm{mM}$ EDTA, and 0.5

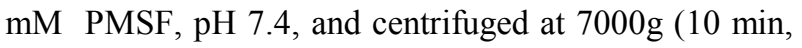
$4^{\circ} \mathrm{C}$ ). The mitochondria (top layer) were washed twice with homogenization buffer and resuspended in $250 \mathrm{mM}$ sucrose and $0.5 \mathrm{mM}$ PMSF. Isolated mitochondria was stored at $-20^{\circ} \mathrm{C}$.

\section{4- Estimation of protein}

The protein content of the mitochondrial preparations was estimated by a method of Lowry et al (1951).

\section{5 - Treatment of mitochondria}

Mitochondria were either incubated for $30 \mathrm{~min}$ at $37^{\circ} \mathrm{C}$ with different concentrations of LCT $(0,5,10,15$, 20 and $25 \mathrm{uM}$ ), or pretreated with $10 \mathrm{uM}$ quercetin for $30 \mathrm{~min}$ and followed by incubation with the same concentrations of LCT for $30 \mathrm{~min}$ at $37^{\circ} \mathrm{C}$. Controls contained either mitochondria only or quercetin.

\section{6- Biochemical analysis}

\subsection{NADH deydrogenase activity}

NADH deydrogenase activity was determind by the method of Galante and Hatefi (1978). Liver mitochondria (30 $\mu \mathrm{g}$ protein) were mixed with a mixture containing $40 \mathrm{mM}$ phosphate buffer, $\mathrm{pH} 7.4,0.1 \%$ sodcholate, $1.5 \mathrm{mM}$ potassium cyanide and $1.3 \mathrm{mM}$ potassium ferricyanide and incubated for $1 \mathrm{~min}$ at $30^{\circ} \mathrm{C}$ then $0.14 \mathrm{mM}$ NADH was added. The decrease in absorption was followed spectrophotometercally at 340 $\mathrm{nm}$ for 1-3 minutes. Specific activity was expressed as nmol NADH oxidized / $\mathrm{min} / \mathrm{mg}$ protein.

\subsection{ATP synthase (ATPase) activity}

The basic idea of this method is to measure the amount of inorganic phosphate produced from the hydrolytic reaction of ATP by the ATPase. Mitochondria (1 $\mathrm{mg}$ protein $/ \mathrm{ml}$ ) were added to a medium containing, $20 \mathrm{mM}$ Tris- $\mathrm{HCl}, \mathrm{pH} 7.6,5 \mathrm{mM}$ $\mathrm{MgCl}_{2}$ and $5 \mathrm{mM} \mathrm{ATP}$. Then the mixture was incubated for $5 \mathrm{~min}$. at $37^{\circ} \mathrm{C}$ in a shaking water bath. The reaction was stopped by the addition of 5\% trichloroacetic acid (TCA), and the inorganic phosphate (Pi) was determined 
colorimetrically as described by Taussky and Shorr (1953). The intensity of the color was measured spectrophotometrically at $740 \mathrm{~nm}$. The concentration of $\mathrm{Pi}$ was calculated graphically from a standard curve and the specific activity was computed as $\mu$ mole $\mathrm{Pi} / \mathrm{mg}$ protein $/ \mathrm{min}$.

\subsection{Superoxide dismutase (SOD) activity}

SOD as enzymatic antioxidant was measured spectrophotometrically at $25{ }^{\circ} \mathrm{C}$ by the method of Marklund and Marklund (1974), with some modifications. The assay medium in a total volume of $1.0 \mathrm{ml}$ containing $50 \mathrm{mM}$ Tris - $\mathrm{HCl}$ buffer $(\mathrm{pH} 8.0)$ and $0.24 \mathrm{mM}$ pyrogallol. Autoxidation of pyrogallol was monitored at $420 \mathrm{~nm}$ for $3 \mathrm{~min}$ in the absence and presence of the enzyme. At least three concentrations of the enzyme which produced between 30 to $60 \%$ inhibition of pyrogallol autoxidation were used. One unit of the enzyme activity is defined as the amount which produced $50 \%$ inhibition of pyrogallol autoxidation under the standard assay conditions. Mitochondrial SOD activities were expressed as Units/ mg protein.

\subsection{Reduced glutathione (GSH) content}

GSH content as a nonenzymatic antioxidant was determined according to the method of Beutler et al. (1963). The method based on the reduction of 5, 5, dithiobis (2- nitrobenzoic acid) (DTNB) with glutathione to produce a yellow complex measured at $405 \mathrm{~nm}$. The reduced chromogen is directly proportional to GSH concentration. The amount of GSH was expressed as $\mu$ mole glutathione oxidized/mg protein.

\section{Statistical analysis}

Data obtained from the experiments were expressed as mean \pm standard deviation (SD). Significant differences of measurement traits were analyzed using one-way analysis of variance (ANOVA) followed by the Student-Newman-Keuls Test. The criterion for statistical significance was set at $\mathrm{p}<0.05$. These test were performed using a computer software CoStat program.

\section{RESULTS and DISCUSSION}

\section{1- Bioenergetics parameters}

Mitochondria are responsible for converting the energy released by electron transport and stored as the binding energy molecule ATP through the oxidative phosphorylation (Hatefi 1985). Xenobiotics that interfere with its synthesis or utilization can be acutely or chronically toxic. Mitochondria carry out a variety of biochemical processes, but their main function is to produce a majority $(>90 \%)$ of cellular ATP. Pesticides have been reported as able to interfere with mitochondrial function, either by inhibiting the respiratory chain or by uncoupling oxidative phosphorylation, and alter the mitochondrial bioenergetics which involved in many diseases (Gomez et al., 2007).

\subsection{NADH deydrogenase (Complex I) activity}

The electron transport chain (ETC) of the mitochondria is the means by which electrons are removed from the reduced carrier NADH and transferred to oxygen to yield $\mathrm{H}_{2} \mathrm{O}$, begins with $\mathrm{NADH}$ deydrogenase. Complex I catalyze the first step of oxidative phosphorylation and, hence, it is the key for the efficient ATP production.

As shown in (Fig .1), liver mitochondria treated with LCT at different concentrations $(5-20 \mu \mathrm{M})$ exhibited significant reduction $(p<0.05)$ in complex I activity in an inversely manner. Mitochondria pretreated with $(10 \mu \mathrm{M})$ quercetin reduced that inhibition and almost keep the enzyme activity to the control value, while quercetin treatment alone induced significant activation $(p<0.05)$. In agreement with the present results, Reiming and Yu-gu (1998) reported that Isophenphos-I markedly inhibited complex I activity in rat liver mitochondria. Sherer et al. (2007) examined the in vitro toxicity and mechanism of action of several putative complex I inhibitors that are commonly used as pesticides. So, the protective effect of quercetin was observed against the toxicated effect of LCT.

Fato et al. (2009) investigated the production of ROS by complex I in isolated open bovine heart submitochondrial membrane fragments during forward electron transfer in presence of NADH. ROS production by complex I is strictly related to its inhibited state. So the inhibition in complex I activity in our results may resulting in decreased oxygen consumption and attributed to increase ROS which alterate the oxidative status of the mitochondria. Complex I is inhibited by more than 60 different families of compounds starting from Rotenone, the prototype of this series, to a number of synthetic insecticides/acaricides (Degli, 1998).

\subsection{ATP synthase (ATPase) activity}

Results represented in (Fig.2) revealed that, ATPase activity was significantly $(\mathrm{P}<0.05)$ decreased in the LCT treated mitochondria in all tested concentrations in a concentration dependant manner (inversely proportion), while the quercetin alone significantly increased the activity. The pretreated mitochondria with quercetin relatively preserved the activity of the enzyme. The same results were obtained with other pesticides (Desaiah and Mehendale 1977; Ruder et al., 1991; Dugravot et al., 2003; Castanha Zanoli et al., 2012). 


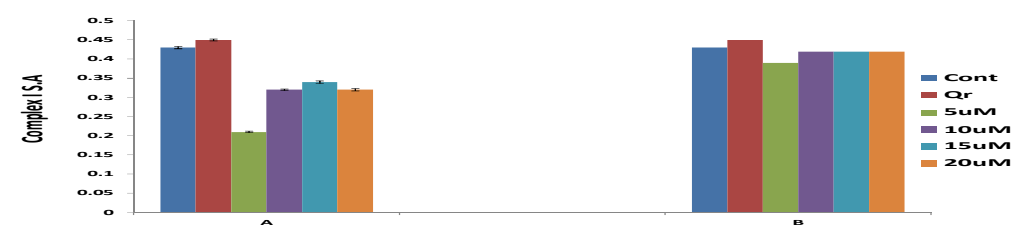

Fig. 1. Change in Complex I specific activity (S.A) of rabbit liver mitochondria treated with lambda cyhalothrin (LCT) at different concentrations (A) and the pretreated mitochondria with 10uM qurcetin (Qr) followed by LCT (B). The values are expressed as means \pm SE. $n-$ Values $=5$

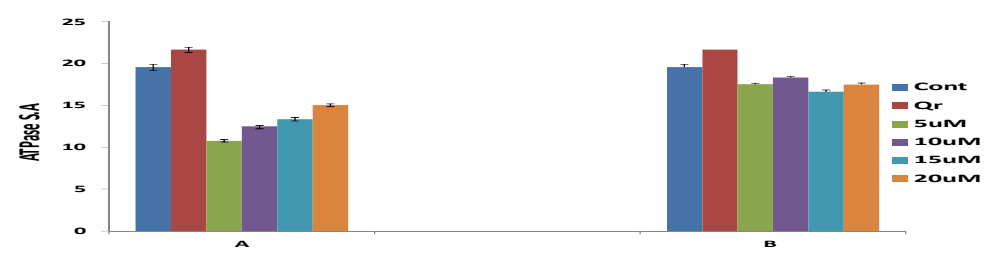

Fig. 2. Change in ATP ase specific activity (S.A) of rabbit liver mitochondria treated with lambda cyhalothrin (LCT) at different concentrations (A) and the pretreated mitochondria with 10uM qurcetin (Qr) followed by LCT (B). The values are expressed as means \pm SE. $n-$ Values $=5$

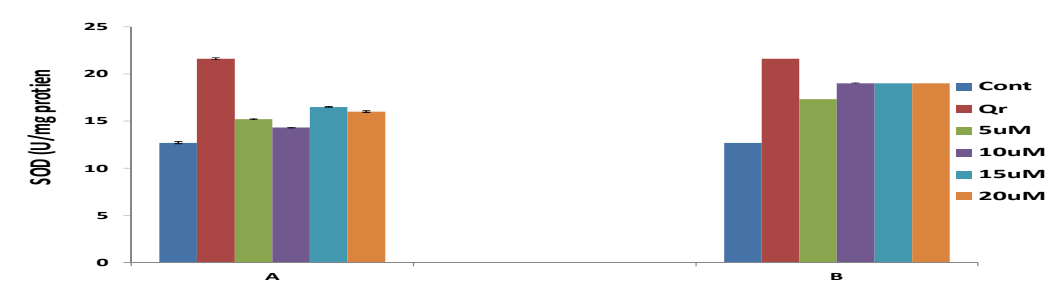

Fig. 3. Change in SOD activity of rabbit liver mitochondria treated with lambda cyhalothrin (LCT) at different concentrations (A) and the pretreated mitochondria with 10uM qurcetin (Qr) followed by LCT (B). The values are expressed as means $\pm \mathrm{SE}$. $\mathrm{n}-$ Values $=\mathbf{5}$

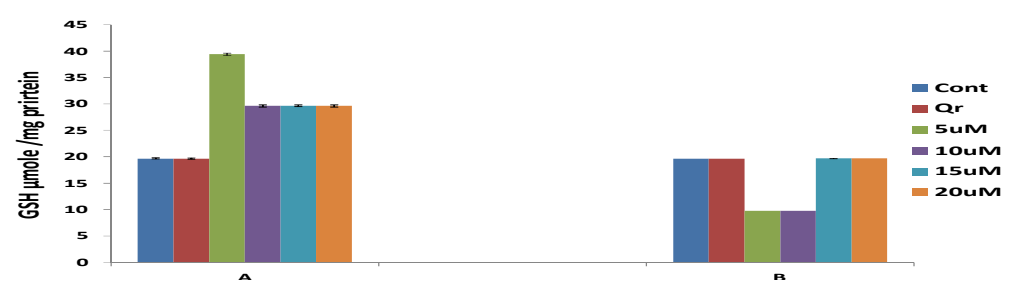

Fig 4. Change in GSH content of rabbit liver mitochondria treated with lambda cyhalothrin (LCT) at different concentrations (A) and the pretreated mitochondria with 10 uM qurcetin (Qr) followed by LCT (B). The values are expressed as means \pm SE. $n-$ Values $=5$ 


\section{2- Antioxidants Parameters}

Mitochondria are the primary intracellular site of oxygen consumption and the major source of ROS, most of them originating from the ETC. In accordance with this, it has been estimated that the steady state concentration of superoxide in the mitochondrial matrix is 5-to10 fold higher than in the cytosol (Cadenas and Davies 2000). Associated with this constant flow of ROS generation, mitochondria are also a target for the damaging effects of oxygen radicals (Fernandez-Checa and Kaplowitz 2005; Kaelin 2005; Orrenius et al., 2007). Although ROS generated under physiological conditions are not harmful, and likely play a signaling role, toxic or pathological conditions that lead to an impairment of mitochondrial function can increase the release of ROS. Mitochondria efficiently reduce free radicals under normal conditions predominantly through antioxidant mechanisms, including SOD as well as GSH (Wheeler et al., 2001).

\subsection{Superoxide dismutase (SOD) activity}

Fig. (3) Show that SOD activity was significantly increased $(p<0.05)$ in the LCT treated mitochondria compared to control in concentration dependent manner and that activation was increased in the quercetin pretreated mitochondria.The antioxidant enzymes in mitochondria such as SOD which dismutate $\mathrm{O}_{2}{ }^{-}$, may counteract pyrethroid-induced oxidative stress. The increase in SOD activity in mitochondria after pyrethroid intoxication appears to be due to increased generation of ROS. These results in line with Lukaszewicz-Hussain and Moniuszko-Jakoniuk (2004) who indicated that chlorfenvinphos induces oxidative stress to rat liver mitochondria. The increased oxidative stress resulted in an increase in the activity of SOD (Kale et al., 1999).

\subsection{Reduced glutathione (GSH) content}

GSH is a major mitochondrial antioxidant that protects mitochondrial DNA (mtDNA) against oxidative damage by reducing $\mathrm{H}_{2} \mathrm{O}_{2}$ via glutathione peroxidase (Mari et al., 2013). The results revealed significant increase $(p<0.05)$ in GSH content in the LCT treated mitochondria, especially at the low concentration $(5 \mu \mathrm{M})$ and return to the normal value in the qurcetin pretreated mitochondria especially at 15 and $20 \mu \mathrm{M}$ of LCT. Treatment with qurcetin alone did not affect the content of GSH (Fig. 4).The increase in reduced glutathione (GSH) content in mitochondria may probably be an initial adaptive response to the increased oxidative stress in pyrethroid intoxicated liver. GSH provide the $-\mathrm{SH}$ group for conjugation by glutathione- $S$ transferase (GST), which detoxifies a variety of electrophilic compounds to less toxic forms. It is probable that the initial increase in mitochondrial GSH provide SH for GST activity to decrease pyrethroid toxicity (Kale et al. 1999).

\section{CONCLUSION}

Mitochondrial dysfunction is a fundamental pathogenic mechanism that leads to several significant toxicities in mammals, especially those associated with the liver (Szewczyk and Wojtczak, 2002; Amacher, 2005). To assess the potential involvement of mitochondria in LCT-related hepatotoxicity, we assessed its effects on the bioenergetics and the oxidative status of liver mitochondria, and the role of quercetin as a natural antioxidant to mitigate LCT injurious effect. The present study showed that LCT perturbs the mitochondrial bioenergetics and the antioxidants defence parameters, hence quercetin played a good role to protect the mitochondria. These effects constitute a potential mechanism for LCT toxicity in liver cells, which could contribute to the toxicological effects of LCT in animals and human.

\section{REFERENCES}

Abdel Aziz, K.B. and H.M. Abdel Rahem 2010. Lambda, the pyrethroid insecticide as a mutagenic agent in both somatic and germ cells. J. Am. Sci. 6: 317-326.

Abdel-Razik, R.K. and N.A. Hamed 2015.Deleterious Effect of Abamectin on Rat Brain Mitochondria. Alex. Sci. Exch. J. 36: $422-428$.

Adewole, S.O., E.A. Caxton-Martins and J.A. Ojewole 2007. Protective effect of quercetin on the morphology of pancreatic b-cells of streptozotocin-treated diabetic rats. Afr. J. Tradit. Complement Altern. Med. 4:64-74.

Amacher, D.E. 2005. Drug-associated mitochondrial toxicity and its detection. Curr. Med. Chem. 12: 1829-1839.

Betler, E, O. Duron and B.M. Kellin 1963. Improved method for the determination of blood glutathione. J. Lab. Clin. Med. 61: 882-888.

Cadenas, E and K.J. Davies 2000. Mitochondrial free radical generation, oxidative stress, and aging. Free Radic. Biol. Med. 29: 222-230.

Cassarino, D.S. and J.P. Bennett 1999. An evaluation of the role of mitochondria in neurodegenerative diseases: mitochondrial mutations and oxidative pathology, protective nuclear responses, and cell death in neurodegeneration. Brain Res. Rev. 29: 1-25.

Castanha Zanoli, J.C., M.A. Maioli, H.C.D. Medeiros and F.E. Mingatto 2012. Abamectin affects the bioenergetics of liver mitochondria: A potential mechanism of hepatotoxicity.Toxicol. in Vitro, 26:51-56.

Degli, E.M.1998. Inhibitors of NADH-ubiquinone reductase: an overview. Biochem. Biophys. Acta.1364:222-235. 
Desaiah, D., I.K. Ho and H.M. Mehendale 1977.Effects of Kepone and Mirex on mitochondrial $\mathrm{Mg}^{2+}$-ATPase activity in rat liver. Toxicol. Appl. Pharm. 2: 219-228.

Droge, W. 2002. Free radicals in the physiological control of cell function. Physiol. Rev. 82:47-95.

Dugravot, S., F. Grolleau, D. Macherel, A. Rochetaing, B. Hue, M. Stankiewicz, J. Huignard and B. Lapied 2003. Dimethyl Disulfide Exerts Insecticidal Neurotoxicity.Through Mitochondrial Dysfunction and Activation of Insect $\mathrm{K}^{+}$ ATP Channels. J. Neurophysiol. 90: 259-270.

El-Demerdash, F.M. 2007.Lambda-cyhalothrin-induced changes in oxidative stress biomarkers in rabbit erythrocytes and alleviation effects of some antioxidants. Toxicol. In Vitro 21: 392-397.

Fato, R., C. Bergamini, M. Bortolus, A.L. Maniero, S. Leoni, T. Ohnishi and G. Lenaz 2009. Differential effects of mitochondrial Complex I inhibitors on production of reactive oxygen species. Biochem. Biophys. Acta.1787: 384-392.

Fernandez-Checa, J.C. and N. Kaplowitz 2005.Hepatic mitochondrial glutathione: transport and role in disease and toxicity. Toxicol. Appl. Pharmacol. 204: 263-273.

Fetoui, H., M. Garoui, F. Makni-Ayadi and N. Zeghal 2008. Oxidative stress induced by lambda-cyhalothrin (LTC) in rat erythrocytes and brain: attenuation by vitamin C. Environ. Toxicol. Pharm. 26: 225-231.

Fetoui, H., M. Makni, M. Garoui and N. Zeghal 2010.Toxic effects of lambda-cyhalothrin, a synthetic pyrethroid pesticide, on the rat kidney: Involvement of oxidative stress and protective role of ascorbic acid. Exp. Toxicol. Pathol. 62: 593-599.

Galente, Y.M. and Y. Hatefi 1978. Resolution of complex I and isolation of NADH dehydrogenase and an iron-sulfur protein. Methods Enzymol. 53: 15.

Gomez, C., M.J. Bandez and A. Navarro 2007.Pesticides and impairment of mitochondrial function in relation with the parkinsonian syndrome. Frontiers in Biosci. 12:10791093.

Gram, T.E., L.K. Okine and R.A. Gram 1986. The metabolism of xenobiotics by certain extrahepatic organs and its relation to toxicity. Annu. Rev. Pharmacol. Toxicol. 26: 259-291.

Hatefi, Y. 1985. The mitochondrial electron transport and oxidative phosphorylation system. Annu. Rev. Biochem. 54:1015-1069

Ikizler, M., N. Erkasap, S. Dernek, T. Kural and Z. Kaygisiz 2007.Dietary polyphenol quercetin protects rat hearts during reperfusion: enhanced antioxidant capacity with chronic treatment. Anadolu Kardiyol. Derg. 7:404-410.

Ji, L.L. 1999. Antioxidants and Oxidative Stress in Exercise. Proc. Soc. Exp. Biol. Med. 222:283-292

Kaelin, W.G.Jr 2005.ROS: really involved in oxygen sensing. Cell Metab. 1:357-358.
Kale, M., N. Rathore, S. John and D. Bhatnagar 1999. Lipid peroxidative damage on pyrethroid exposure and alterations in antioxidant status in rat erythrocytes: a possible involvement of reactive oxygen species. Toxico. Lett. 105: 197-205.

Kalender, Y., S. Kaya, D. Durak, F.G. Uzun and F. Demir 2012. Protective effects of catechin and quercetin on antioxidant status, lipid peroxidation and testishistoarchitecture induced by chlorpyrifos in male rats. Environ. Toxicol. Pharmacol. 33:141-148.

Krause, F., N.H. Reifschneider, S. Goto and N.A. Dencher 2005. Active oligomeric ATP synthases in mammalian mitochondria. Biochem. Biophys. Res. Commun. 329: 583-590.

Lim, S., S.Y. Ahn, I.C. Song, M.H. Chung and H.C. Jang 2009.Chronic Exposure to the Herbicide, Atrazine, Causes Mitochondrial Dysfunction and Insulin Resistance. PLoS. ONE 4: 1-11.

Lowry, O.H., N.J. Rasebrough, A.L. Farr, R.J. Randall 1951. Protein measurement with the folin phenol reagent. Biol. Chem. 193: 265.

Lukaszewicz-Hussain, A. and J. Moniuszko-Jakoniuk 2004.Chlorfenvinphos, an Organophosphate Insecticide, Affects Liver Mitochondria Antioxidative Enzymes, Glutathione and Hydrogen Peroxide Concentration. Pol. J. Environ. 13: 397-401.

Mari, M., A. Morales, A. Colell, C. Garcia-Ruiz, N. Kaplowitz and J.C. Fernandez Checa 2013. Mitochondrial glutathione: features, regulation and role in disease. Biochem. Biophys. Acta.1830: 3317-3328.

Marklund, S. and G. Marklund 1974. Involvement of the superoxide anion radical in the autoxidation of pyrogallol and a convenient assay for superoxide dismutase. Eur. J. Biochem. 47:469-474.

Michelangeli, F., M.J. Robson, J.M. East and A.G. Lee 1990. The conformation of pyrethroids bound to lipid bilayers. Biochem. Biophys. Acta. 1028: 49-57.

Muhammad, F., M. Akhtar, Z.U. Rahman, H.U. Farooq, T. Khaliq and M.I. Anwar 2010. Multi-residue determination of pesticides in the meat of cattle in Faisalabad- Pakistan. Egypt Acad. J. Biol. Sci 2: 19-28.

Oliveira, C., V.S. Vassilieff and I. Vassilieff 2000. Residues and placental transfer of lambda-cyhalothrin in goats. J. Vet. Res. 4: 146-152.

Orrenius, S., V. Gogvadze and B. Zhivotovsky 2007.Mitochondrial oxidative stress: implications for cell death. Annu. Rev. Pharmacol. Toxicol. 47:143-183.

Pardini, R.S., J.C. Heidker , T.A. Baker and B. Payne 1980.Toxicology of various pesticides and their decomposition products on mitochondrial electron transport. Arch. Environ. Contam. Toxicol. 9:87-97.

Pereira, S.P., M.A. Fernandes , J.D. Martins , M.S. Santos , A.J. Moreno , J.A. Vicente, R.A. Videira and A.S. Jurado 2009. Toxicity assessment of the herbicide metolachlor comparative effects on bacterial and mitochondrial model systems. Toxicol. In Vitro. 23:1585-90 
Rei-ming, L. and L. Yu-gu 1988. Effects of Isophenphos-I on the Respiratory Function of Rat Liver Mitochondria. J Tongji Med. Univ. 8:18-23.

Ruder, F.J., W. Guyer, J.A. Benson, H. Kayser 1991.The thiourea insecticide/acaricide diafenthiuron has a novel mode of action: Inhibition of mitochondrial respiration by its carbodiimide product. Pestic. Biochem. Phys. 41: 207219.

Sherer, T.B., J.R. Richardson, C.M. Testa, B.B. Seo, A.V. Panov, T. Yagi, A. Matsuno-Yagi, G.W. Miller and J.T. Greenamyre 2007. Mechanism of toxicity of pesticides acting at complex I: relevance to environmental etiologies of Parkinson's disease. J. Neurochem. 100:1469-1479.

Szewczyk, A. and L. Wojtczak 2002. Mitochondria as a pharmacological target. Pharmacol. Rev. 54: 101-127.

Taussky, H.H. andE. Shorr 1953.With the technical assistance. Amicrocolorimetric method for the determination of inorganic phosphorus. J. Biol. Chem. 253: 956-964.
Tebourbi, O., M. Sakly and K. Ben Rhouma 2011. Molecular Mechanisms of Pesticide Toxicity.In: Pesticides in the Modern World-Pests Control and Pesticides. Exposure and Toxicity Assessment, ed. Margarita Stoytcheva. InTech Publisher under CC BY-NC-SA 3.0 license.297332.

Turgut, C., H. Ornek and T.J. Cutright 2011. Determination of pesticide residues in Turkey's table grapes: the effect of integrated pest management organic farming and conventional farming. Environ. Monit. Assess. 173: 315323.

Wheeler, M.D., M. Nakagami, B.U. Bradford, T. Uesugi, R.P. Mason, H.D. Connor, A. Dikalowa, M. Kadiiska and R.G. Thurman 2001.Overexpression of mangenase superoxide dismutase prevents alkohol-induced liver injury in the rat. J. Biol. Chem. 276: 36664.

$$
\begin{aligned}
& \text { الماخص العربي } \\
& \text { التأثير الوقائي للكيرسيتين ضد الاكسدة ونقص الطاقة البيولوجية فى الميتوكوندريا التي يسبيها } \\
& \text { لامبادا سيهالوثرين } \\
& \text { نادية على حامد } \\
& \text { المعايير التي شملتها الدر اسة. }
\end{aligned}
$$

